\title{
Vertical Tax Equity: An Analysis of ResidentialValuation in a Major U.K. City
}

McGreal, S., Brown, L., Adair, A., \& Webb, JR. (2007). Vertical Tax Equity: An Analysis of ResidentialValuation in a Major U.K. City. Journal of Housing Research, 16(1), 1-18.

Link to publication record in Ulster University Research Portal

Published in:

Journal of Housing Research

Publication Status:

Published (in print/issue): 01/01/2007

\section{Document Version}

Publisher's PDF, also known as Version of record

\section{General rights}

Copyright for the publications made accessible via Ulster University's Research Portal is retained by the author(s) and / or other copyright owners and it is a condition of accessing these publications that users recognise and abide by the legal requirements associated with these rights.

\section{Take down policy}

The Research Portal is Ulster University's institutional repository that provides access to Ulster's research outputs. Every effort has been made to ensure that content in the Research Portal does not infringe any person's rights, or applicable UK laws. If you discover content in the Research Portal that you believe breaches copyright or violates any law, please contact pure-support@ulster.ac.uk. 


\section{Vertical Tax Equity: An Analysis of Residential Valuation in a Major U.K. City \\ Stanley McGreal, Louise Brown, Alastair Adair, and James R. Webb}

\section{Abstract}

This study uses a sample of houses sold in 2005 in the Belfast metropolitan area (UK) to test the accuracy of single-family residence valuations and whether the valuation for tax purposes is significantly different than market value as evidenced by sale price. This study examines how accurately the assessed values reflect market value, whether there are differences across statistical distributions and whether differences between assessed value and market value can be attributed to particular property characteristics. The results indicate that there is a tendency to over-value lower priced properties and under-value higher priced property demonstrating regressive vertical tax inequity. In addition, the net economic effect of valuation inaccuracy is shown to be a modest gain in revenue but one that is unequally distributed across house owners.

The accuracy of, and bias in, the valuation process has been the subject of research studies dealing with mainly the commercial property market and to a lesser extent the residential market. In particular, there has been considerable debate regarding whether valuations are accurate to within 5\%,10\%, 15\% or some other limit of the market price. However, often there has not been sufficient evidence to test such claims due to problems of obtaining sufficiently large sample sizes where both valuation and transaction evidence is available. In this respect, the value assessment of residential real property in Northern Ireland provides an opportunity to compare the assessed value with market value (price). The differing concepts of price and value have been reviewed from a literature perspective by McParland, McGreal, and Adair (2000). It is not the intention of this study to re-open this debate, but rather to test whether there are any systematic influences in the assessment process that may result in the over-valuation or under-valuation of residential real estate with particular physical or location characteristics and which only become apparent on an ex-post basis.

The paper proceeds as follows. Next there is a discussion of the concepts of price, value, and valuation accuracy, followed by a review of the literature on vertical tax equity. This is followed by a discussion of real property assessments in Northern Ireland, along with further consideration of the data under-pinning the analysis. The results and findings are then discussed and their economic impact is explored. The paper closes with concluding remarks. 


\section{Value and Price: Valuation Accuracy Debate}

In the United Kingdom, the valuation of single-family houses is normally undertaken on the basis of market value as defined by the RICS Appraisal Manual or Red Book (RICS, 2003). Market value is an attempt to identify the exchange price in the market place at the date of valuation. Exchange prices for real estate are determined by the information available to buyers and sellers. Valuations, as proxies for prices, are a function of information. Gallimore (1996) maintains that valuations are a function of the way in which valuers process information.

Comparables are the cornerstone of the market valuation process. They are perceived to be the most reliable evidence, but the time taken for transactions to complete means that, of necessity, they occur before the subject property valuation date. Hence, different studies suggest that assessed values lag market values as evidenced by actual prices in the market place (Crosby, 2000; and Matysiak and Wang, 1995) and can account for some of the difference between assessed value and market value. Authors such as Geltner (1993) and Gallimore (1996) argue that this outcome is a rational result of valuers anchoring on past transaction information.

Accuracy, variation, and bias underpin the behavioral research literature on the valuation process. Valuation accuracy is the ability of a valuation to correctly capture the predetermined basis of value (Crosby, 2000). In accuracy studies, this target is usually taken as a subsequent sale price transacted in the market place. Valuation variation is defined as the inability of two or more valuers to produce the same valuation for the same property at the same time. Variation is therefore measured as the difference between valuations. Valuation bias is where valuers consistently under or overvalue in relation to the predetermined objective; in the case of accuracy where valuations are consistently under or over the sale price and in variation studies where one valuer is consistently over or under another valuer. This study focuses primarily on valuation accuracy and bias issues.

Gallimore (1996) argues that since valuations are the product of human judgment, such judgment may incorporate elements of cognitive bias, which in turn leads to 'inaccuracy' in valuations. Gallimore questions the validity of the rational assumptions that underlie models of valuation behavior and focuses on confirmation bias as one form of deviation from rationality. The measure of valuer performance in undertaking valuations is usually subsumed within the concept of valuation accuracy. As Brown (1992) has pointed out, there are separate components to this: first, the capability of valuers to process in a consistent manner the information set; and second, their ability to reflect accurately the reaction of market participants to that information. The distinction is essentially that of the reliability and validity of valuations.

Valuation is perceived to be very much a matter of opinion as amply demonstrated by Crosby (2000) in an analysis of legal cases decided by the senior courts in the United Kingdom. "Valuation is not an exact science; it involves questions of judgement on which experts may differ without forfeiting their claim to professional competence," [Zubaida $v$ Hargreaves, (1995), 1EGLR 127]. It is clear that while "pinpoint accuracy" is not expected, the courts have not legitimized inaccuracy. In a number of cases in the U.K., the concept of a margin of error has been utilized to decide on a bracket outside of which 
the value should not fall. Despite courts accepting that perfect accuracy is unobtainable, it appears that specific lines can be drawn; in the U.K. this is around $10 \%-15 \%$ either side of a notional correct value. This is largely in accordance with Crosby's observation that nearly $75 \%$ of decisions fall within a bracket of $10 \%-15 \%$. Although valuation accuracy is not really an issue in negligence cases, a number of accuracy studies have had their results interpreted in the light of the margin of error concept.

The main empirical studies of valuation accuracy and bias in the U.K. focus on the commercial rather than the residential market (Brown, 1985; Lizieri and VenmoreRowland, 1991; Matysiak and Wang, 1995; McAllister, 1995; and Drivers Jonas/IPD, 1997). One of the largest studies dealing with commercial property was carried out by the Investment Property Databank in conjunction with Drivers Jonas (Drivers Jonas/IPD, 1988). The results of the preliminary study indicated a conservative bias in valuations (Crosby, 2000). In a second phase of the study it was shown that the number of valuations that fell within $10 \%$ of the sale price was $30 \%$. The number of valuations falling within $20 \%$ was $67 \%$ with $33 \%$ of the valuations falling outside the $20 \%$ bracket. According to Crosby, these figures hide a distinctive and improving trend. Since 1992, the proportion of valuations within 20\% of the sale price has increased to 80\%, whereas between 1982 and 1991, the number of valuations within $20 \%$ averaged only $63 \%$. However, the studies by Drivers Jonas/IPD $(1988,1997)$ provide evidence of substantial mismatch between the valuation and the subsequent price, which cannot simply be explained by market movements, though Crosby concluded that valuers undervalue in bull markets and overvalue in bear markets.

At an international level, Crosby (2000) reviewed valuation accuracy studies in Australia, the United States, and the U.K. He concluded that the accuracy of valuations in the U.K. is about half that of the U.S. and Australia. However Crosby tempers the results with an awareness of the limitations of the methodology. There are theoretical difficulties in reconciling the definition of market value to actual sale price and practical difficulties in finding a sale price at the same or similar time as the valuation, so introducing the problem of adjusting for time between the events. For these reasons among others, the interpretation of the same data may not always be consistent and the subject of valuation accuracy remains a live debate for both commercial and residential property.

\section{Vertical Tax Inequity}

There has been extensive discussion on the concepts of both horizontal (Allen and Dare, 2002; and Haurin, 1988) and vertical tax inequity in property tax systems (Paglin and Fogarty, 1972; Kochin and Parks, 1982; Clapp, 1990; Sirmans, Diskin, and Friday, 1995; and Benson and Schwartz, 2000). The literature focuses on the methodological approach to tax equity and the creation and testing of models. Vertical tax inequity is seen to occur where there is a systematic variation of assessed value from market value across property value ranges. It is described as progressive if the lower-priced properties are systematically undervalued compared to the higher-valued properties and regressive if the lower-priced properties are being overvalued in comparison to the higher-priced properties. In this study, it is argued that the computer-assisted mass appraisal (CAMA) model employed in the valuation of properties for rating (tax) purposes in Northern Ireland systematically 
over valued lower-priced properties and undervalued higher-priced properties therefore demonstrating regressive vertical tax inequity.

The literature presents several models to assess the presence and extent of vertical tax inequity. An early model by Paglin and Fogarty (1972) analyzed tax inequity through an assessed value/market value ratio using market value as a proxy for real value. Kochin and Parks (1982) argue that an assessed value is a better predictor. Clapp (1990) challenged the validity of Kochin and Parks model and proposed a 2SLS model to adjust sales prices to the date of assessed value. Sirmans, Diskin, and Friday (1995) applied six different models to a sample of properties $(1,508)$ for Miami, Florida and concluded that each model had a tendency to give different and contradicting results. In their analysis, Sirmans et al. and Smith (2000) adjusted the sales prices using a house price index as a proxy for market value at a given time to facilitate a more accurate comparison. However, Sirmans et al. suggested that using the sales price as a proxy for market value has a tendency to yield results indicating a regressive tax system compared to those that used assessed value as a proxy for market value that have a tendency to progressivity.

Benson and Schwartz (1997) offered some reasons for the inaccuracy of assessed values; namely that higher value properties tend to be more unique and with limited resources an assessor may not be able to adequately quantify the added value of interior design. Secondly, in an effort to avoid an excessive number of appeals, it may be advantageous to undervalue higher-priced properties. Benson and Schwartz when investigating vertical inequity results over two reassessment cycles in Bellingham, Washington suggested that one of the contributing factors to the validity of the assessment values is the rate of increase that has taken place during the reassessment process. This paper raises similar questions and acknowledges the difficultly that assessors face when attempting to give accurate valuations in a period of rapidly escalating price increases.

\section{Northern Ireland Capital Value Rating}

The Northern Ireland Executive embarked on a Review of Rating Policy in 2000 as the previous revaluation of domestic property, in 1976, was based on an inherited and unreformed system of residential rental values. The review sought to address the many shortcomings, inequities and anomalies created by the rental value-based system and changes in market values since 1976, and to establish a fairer way to share the burden of local taxation and help to meet the costs of regional and local public services (Northern Ireland Executive, 2003). Since the housing market is dominated by owner-occupiers, the overwhelming number of property transactions relate to capital sales. The availability of market information and the desire to achieve a progressive property taxation system led to the decision to adopt a discrete capital value approach. The banded approach utilized elsewhere in the U.K. was considered to be more regressive in nature.

The transition in Northern Ireland from a valuation system based on discrete hypothetical rental values to one anchored on discrete market values is a significant change. The evidence base for the rental value system was not only extremely thin, but involved the added complication of moving from a gross rental value by deducting standardized management and other expenses to arrive at a hypothetical net annual value, as defined 
by statute. While the evidence base for discrete market values is much greater, the valuation approach relies on the accurate analysis of prices for properties that have sold and the application of the value attributes to the remaining population of houses on an individual basis. Consequently, errors or biases in the approach are more likely to be highlighted under the discrete market value system than under a banded valuation regime, where the accuracy of the valuation focuses more on the boundary from one band to another rather than on the range of the values within the band. The introduction of discrete market values in Northern Ireland is novel, since the remaining jurisdictions in the U.K. rely on the banded system.

At an international level, there are many examples of the use of discrete market values as the basis for local property taxes. The U.S., New Zealand, Australia, Canada, the Netherlands, and South Africa have all adopted discrete market values as the basis for their respective residential property tax systems (McCluskey, Davis, and Lim, 2003). The rationale for such widespread use is simply that individual assessments based on market value are likely to be more accurate and equitable, can be monitored more effectively, and are more readily understood and evaluated by taxpayers.

The process of arriving at discrete market values recognizes that the property market is not perfect and sale prices for similar houses often differ for little apparent reason. Part of the explanation may be due to the fact that houses in Northern Ireland are usually sold by private treaty with an individual bidding process taking place. Moreover, since the real estate information markets are not efficient, most purchasers do not have the necessary information to make precise judgments on what to bid. This may result in nearly identical houses being sold, at the same point in time, for significantly varying amounts.

The methodology employed in Northern Ireland to derive the market values, use as the basis of the valuation, natural variability based on an 'average predicted value'. This is further defined as an assessed value falling within certain tolerances (Northern Ireland Executive, 2003). Tolerances are defined in terms of properties being fitted out internally to a standard appropriate to the type, age, and location of the property (e.g., it is assumed that the house has a standard kitchen and bathroom for its age, type, and location). Reflecting slight differences in internal fit-out would be extremely time consuming, difficult and subjective. However, to allow for houses that are in particularly poor order, it would be possible to reflect actual external condition. This approach is consistent with practice under the former rental value system and also sits comfortably with council tax arrangements in the rest of the U.K. Any value attributable to development potential is disregarded under the assessment and an assumption made that use is restricted to the existing use. In contrast, market value takes into consideration the external and internal condition of the property; hence, the assessed or average predicted value may not equate with market value in all cases.

Under the model applied in Northern Ireland, all residential properties were valued as at January 1, 2005 employing market evidence on this date to produce valuation models as part of a CAMA approach. Such an approach has been used internationally in valuation exercises for property taxation purposes. However, the CAMA model used in Northern Ireland was based on a limited number of property characteristics, namely property type, property size, central heating, and whether the property had a garage. All properties 
were assumed to be in an average condition internally taking into account age, type, and locality. The discrete value assessed for each property was checked by the responsible agency, the Valuation and Lands Agency for Northern Ireland (VLA) and, if required, manually adjusted to ensure that the values are as accurate as possible. In Northern Ireland, there is no legal requirement to report house sales to one agency, which is unlike the U.S. where information is passed to the county authorities on the date of sale.

\section{Data Sources and Approach}

In order to analyze the variation between the assessed value and the market value as evidenced by the achieved transaction price, a combined database was developed to include information from the former with sales drawn from a survey of the market. ${ }^{1}$ The latter dataset includes information on the transaction price and the date of sale, together with characteristics for the property, namely address, location (postcode), house type, age, size, number of rooms, heating, garage, and condition. The assessed value database contains similar, though more limited, information on postal address, house type, size, and assessed value. The two datasets were compared on an exact address match using house number and postcode to ensure the validity of each subject property.

For the purpose of this analysis, a sample of sales in the Belfast Metropolitan Area (BMA) over the period January through June 2005 was used so that there was comparability with the date of the assessed value. The results of preliminary tests (Exhibit 1) indicate that the validity of the assessed values is significantly eroded within a six-month period and that the level of price increase over this period $(3.84 \%$ in quarter 1 and 5.65\% in quarter 2) was sufficient to result in the assessed values becoming increasingly dated with a sharply increasing incidence of under-valuation. ${ }^{2}$ The large chi-square value of 112.5 $(p=.001)$ shows a highly significant difference in properties under-valued and those over-valued on the basis of unadjusted sale price.

As the analysis sought to test valuation accuracy and in particular to assess whether the assessed value reflects market value, it is necessary to make the datasets as fully compatible as possible. Hence the transaction evidence was transformed by indexing the

Exhibit 1. Comparing the Distribution of Properties between January and March and April and June 2005 Using Unmodified Data

\begin{tabular}{lcc} 
& January-March 2005 & April-June 2005 \\
\hline$\%$ overvalued & 40.7 & 30.0 \\
$\%$ undervalued & 59.4 & 70.0 \\
Total number of sales transactions & 720 & 834 \\
Rate of quarterly increase & 3.84 & 5.65 \\
Chi-square & $8.725^{* * *}$ & $112.5^{* * *}$ \\
\hline
\end{tabular}


sales price back to January 2005 using the quarterly appreciation figures. Thus, the values for 2005 , quarter one, were decreased by $1.92 \%$, which is one-half the appreciation over the first quarter of 2005 (3.84\%) and the values for quarter two were decreased by the total appreciation for quarter one plus half of the quarterly appreciation for quarter two (5.65\%). This allowed the property values for the assessed values and the market values to be directly compared with each other.

The combined dataset contains information on 1,554 properties in the BMA distributed between the two quarters. The majority of the sample consisted of semi-detached (545), terraced (464), and detached houses (267). There was a smaller representation of semidetached and detached bungalows and apartments. These statistics are consistent with the profile of the housing stock in the area. Four sub-markets within the BMA, which had been utilized in previous studies and are defined by the city's geography and socioeconomic characteristics were also examined, namely the North and West of Belfast (the lowest priced sub-market), the Outer North (the next lowest priced sub-market), the South including Lisburn (the highest priced), and the East (including North Down).

\section{Analysis: Comparison of Distributions}

\section{Aggregated Analysis on the Indexed Dataset}

The first stage of the analysis focuses on the respective distributions independently, the assessed values, and the house price transactions indexed back to January 1, 2005. Comparison of the summary statistics indicates a high level of similarity in the two distributions. The mean value for the assessed values is higher $(£ 128,602)$ than the transaction prices $(£ 127,301)$, but the difference is small and not statistically significant. However, an important issue is the higher figure for the valuation, contrary to the position in the literature, which suggests that valuations should lag the price information. The standard deviation, skewness, and kurtosis are indicative of similar distributions at the aggregated level of analysis (Exhibit 2).

Comparison of the two distributions based on percentiles suggests a similarity between the data sets. It also provides evidence that the sales price lags the valuation, notably for lower-priced properties, though the pattern is not entirely consistent. For example, the first quartile of the sales price distribution is $£ 86,635$ compared to $£ 90,000$ for the first quartile of the assessed valuation distribution and for the third quartile the sales price is

Exhibit 2. Comparison of Summary Statistics: Sales and Valuation Distributions

\begin{tabular}{lrr} 
Statistical Parameter & Sales Price & Valuation \\
\hline Mean & $£ 127,301$ & $£ 128,602$ \\
Standard deviation & $£ 68,726$ & $£ 69,027$ \\
Skewness & 2.45 & 2.54 \\
Kurtosis & 10.05 & 10.79 \\
\hline
\end{tabular}


$£ 147,174$, compared to $£ 150,000$ for the assessed valuation. At the top end of the distribution (the $90 \%$ percentile), the converse is apparent, namely the sales price (£210,733) exceeds the assessed value $(£ 205,000)$. These distributional differences (Exhibit 3), although not in the extreme, may suggest that if over-valuation is taking place, it is more likely to affect lower-priced property (regressive) and if an under-valuation of property is occurring that this takes place for the highest-priced property.

\section{Disaggregated Analysis}

The second phase of the analysis is at a disaggregated level and compares, for each of the 1,554 properties, the difference between the sale price indexed to January 1, 2005 and the assessed value and thereby produces a new distribution of value/price differences. This distribution of differences ranges from a property with a valuation $£ 166,856$ below the sale price to the other extreme of a property with an assessed valuation of $£ 182,563$ above the sales price. These represent outliers in both parts of the distribution, which overall has a negative skewness of -0.96 . At the first quartile, the difference between assessed value and sales price, representing undervaluation, was $£ 5,899$. Ten percent of properties were under-valued by $£ 17,344$ or more. In the other half of the distribution, the third quartile of $£ 8,848$, is indicative of over-valuation by this amount and $10 \%$ of properties had an assessed value of $\$ 19,876$ or greater than the adjusted sales price. These statistics infer on a disaggregated basis that substantial differences are apparent between the assessed value and the indexed transaction price for a significant number of properties. Also it would seem that the scale of the price difference is higher for those properties that are over-valued compared to those that are under-valued.

Across the distribution, $26 \%$ of properties were undervalued by up to $£ 10,000,10 \%$ by between $£ 10,000$ and $£ 19,999,3 \%$ by $£ 20,000$ to 229,999 , and $5 \%$ by more than $£ 30,000$; whereas $33 \%$ of properties were over-valued by less than $£ 10,000,13 \%$ by between $£ 10,000$ and $£ 19,999,4 \%$ by $£ 20,000$ to $£ 29,999$, and $6 \%$ by over $£ 30,000$ (Exhibit 4 ).

Exhibit 3. Distributional Differences: Sales and Valuation Distributions

\begin{tabular}{lcr} 
Percentile & Sales Price & Valuation \\
\hline 10 & $£ 67,651$ & $£ 70,000$ \\
20 & $£ 81,952$ & $£ 82,500$ \\
25 & $£ 86,635$ & $£ 90,000$ \\
30 & $£ £ 1,528$ & $£ 92,500$ \\
40 & $£ 100,215$ & $£ 100,000$ \\
50 & $£ 110,986$ & $£ 110,000$ \\
60 & $£ 121,757$ & $£ 120,000$ \\
70 & $£ 136,381$ & $£ 140,000$ \\
75 & $£ 147,174$ & $£ 150,000$ \\
80 & $£ 159,921$ & $£ 165,000$ \\
90 & $£ 210,733$ & $£ 205,000$ \\
\hline
\end{tabular}


Exhibit 4. Distribution by Over- and Under-Valuation

\begin{tabular}{lcc} 
Price Band & Under-Valued & Over-Valued \\
\hline$<£ 10,000$ & $26 \%$ & $33 \%$ \\
$£ 10,000-£ 19,999$ & $10 \%$ & $13 \%$ \\
$£ 20,000-£ 29,999$ & $3 \%$ & $4 \%$ \\
$>£ 30,000$ & $5 \%$ & $6 \%$ \\
\hline
\end{tabular}

The split between properties under-valued by $44 \%(n=685)$ and those over-valued by $56 \%(n=869)$ based on the assessed value and adjusted sale price differs from the 50 : 50 position. On the basis of random assumptions, it would be expected that the occurrence of under-valued and over-valued properties would balance; the question is whether the current split differs significantly from random expectations. The analysis (chisquare $=21.79, p=.001$ ) indicates that the observed distribution differs from random expectations inferring possible bias within the valuation methodology towards overvaluation relative to under-valuation.

Comparison of the price structure of the under-valued properties against those that have been over-valued provides further evidence that the more expensive properties tend to benefit from under-valuation and that less expensive properties are being over-valued (i.e., regressive vertical tax equity). The difference in the respective price means $(£ 133,581$ for the under-valued group and $£ 122,350$ for the over-valued group) is statistically significant at the 0.001 level $(t=3.208)$, which supports the hypothesis that there is a systematic tendency in the valuation model to under-value higher priced property. This is supported by price evidence across the two subsets with values consistently greater for those properties within the under-valued sub-group (Exhibit 5). To investigate this

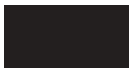

Exhibit 5. Distributional Differences of Price for Under- and OverValued Property

\begin{tabular}{lcc} 
& Sales Price & \\
\cline { 2 - 3 } Percentile & Under-Valued & Over-Valued \\
\hline 10 & $£ 73,097$ & $£ 61,815$ \\
20 & $£ 85,729$ & $£ 78,674$ \\
25 & $£ 92,465$ & $£ 83,857$ \\
30 & $£ 96,609$ & $£ 88,040$ \\
40 & $£ 107,708$ & $£ 95,124$ \\
50 & $£ 116,138$ & $£ 103,962$ \\
60 & $£ 126,550$ & $£ 117,249$ \\
70 & $£ 142,268$ & $£ 132,457$ \\
75 & $£ 154,304$ & $£ 140,489$ \\
80 & $£ 169,108$ & $£ 154,538$ \\
90 & $£ 220,761$ & $£ 191,327$ \\
\hline
\end{tabular}


issue, analysis was undertaken to examine whether those properties that were undervalued by the capital valuation process differed from those over-valued in terms of price, property type, and location within the BMA.

\section{Price Type Variation}

Analysis of under-valued versus the over-valued groups does not suggest any major imbalance of representation by housing type. The two dominant property types in each case are terraced houses (taking 32\% in the under-valued group and $28 \%$ in the overvalued group) and semi-detached houses (34\% of the under-valued group and 36\% of the over-valued group). Detached houses, normally the most expensive property type, comprise $17 \%$ of each sub-group. When each property type is considered independently, it is apparent that terraced houses are the closest to the expectations under random conditions with 222 (47.8\%) under-valued and 242 (52.2\%) over-valued. For semi-detached houses, the largest sub-sector, the distribution is close to that of the overall sample: 233 (42.8\%) are under-valued and 312 (57.2\%) are over-valued, the difference being significant (chi-square $=11.45, p=.001)$. There are also significant differences (0.05 level) in the split between the under and over-valuation for detached bungalows and apartments.

The analysis of market values by housing type (six main types) provides further evidence that those properties that have been under-valued relative to transaction price are the higher-priced properties. Within each of the property types, the assessment methodology consistently under-values the higher-priced property and over-values the lower-priced property, which reinforces the argument that there is a systematic bias in the valuation model. The difference in mean price between the under-valued and over-valued cohorts is statistically significant for three of the property types: terraced houses, semi-detached houses, and detached bungalows (Exhibit 6). For the up-market detached house sector, the price difference between the under-valued and over-valued cohorts is not statistically significant, which suggests that the valuation differences are not so pronounced in the highest priced property $(t=0.04)$. Similarly, for apartment property, much of which has

Exhibit 6. Type and Price Analysis

\begin{tabular}{lcl} 
Property Type & Chi-Square Distribution & Price Means t-test \\
\hline Terrace & 0.86 & $2.80^{* *}$ \\
Semi-detached house & $11.45^{* * *}$ & $4.48^{* * *}$ \\
Detached house & 3.59 & 0.04 \\
Semi-detached bungalow & 2.28 & 1.61 \\
Detached bungalow & $4.45^{*}$ & $2.22^{*}$ \\
Apartment & $3.77^{*}$ & 1.11 \\
All & $21.79^{* * *}$ & $3.21^{* * *}$ \\
\hline
\end{tabular}

Notes:

* Significant at the 0.05 level.

** Significant at the 0.01 level.

*** Significant at the 0.001 level. 
been developed in recent years, there is no significant difference in the mean price between the under-valued and over-valued sub-groups $(t=1.11)$.

\section{Price Area Variation}

Analysis by geographical area, using four spatial sub-markets, raises further insights relating to both the occurrence of under- and over-valuation and the price structure of these respective sub-groups. In three of the four areas, the pattern of over-valuation is more likely than under-valuation, but to differing extents. In the North and West submarket, the distribution statistically adheres to that expected under random conditions with the instance of under-valuation (137 or $47 \%$ ) close to that of over-valuation (153 or $53 \%)$. For the Outer North, the distribution (under-valued 161 or $43 \%$ and over-valued 209 or $57 \%$ ) is similar to that of the overall sample and statistically significant at the 0.01 level (chi-square $=6.23$ ). For the market area in the East of the BMA, the instance of under-valuation relative to over-valuation is substantially different (189 or $36 \%$ undervalued and 330 or $64 \%$ over-valued). The chi-square statistic of $38.31(p=.001)$ indicates a significant deviation from random expectations. In the fourth sub-market, the highpriced South of the BMA, the opposite picture is apparent, with this area being the only sub-market, based on either type or geographical area, to have a greater number of properties under-valued $(n=198)$ than over-valued $(n=177)$, although the difference is not statistically significant.

The pattern of higher-priced property being under-valued compared to lower-priced property is again apparent for each of the four geographical sectors (Exhibit 7). In particular, this is true for the lower-priced sectors, the North and West of the city and the Outer North $(t=3.81, p=.001$ and $t=3.33, p=0.001$, respectively). For the higher-priced sub-markets in the South and East of the BMA, although there are differences in price means between the two sub-groups, these are not statistically significant at the 0.05 level (price differences in the East sub-market is significant at the 0.1 level). Overall, these results support the argument that the valuation model used tends to systematically under-value the higher-priced property and shows regressive behavior. The analysis suggests a complex picture of over- and under-valuation across spatial submarkets

\section{Exhibit 7. Area and Price Analysis}

\begin{tabular}{lll} 
Property Area & Chi-Square Distribution & Price Means $t$-test \\
\hline North \& West city & 0.88 & $3.81^{* *}$ \\
Outer North & $6.23^{* *}$ & $3.33^{* *}$ \\
South \& Lisburn & 1.18 & 0.06 \\
East \& North Down & $38.31^{* * *}$ & 1.91 \\
All & $21.79^{* *}$ & $3.21^{* *}$ \\
\hline
\end{tabular}

Notes:

* Significant at the 0.05 level.

** Significant at the 0.01 level.

*** Significant at the 0.001 level. 
combined with value-price differences that are significant in the lower-priced sub-markets but not significant in the higher-priced sub-markets.

\section{Modeling Price Difference}

In modeling the price difference between the assessed value and the adjusted sale price, over-valuation returns a positive statistic and under-valuation a negative statistic. As price difference is dependent, the $\mathrm{R}^{2}$ in accordance, with expectations, is low (.049) and not a key consideration in this particular analysis. Rather the more important issues relate to price levels of property, property characteristics, and location (Exhibit 8).

First, the analysis indicates a strong negative relationship with the adjusted sale price for properties in the third quartile (51\%-75\%) and fourth quartile $(>75 \%)$ of the distribution: respective $t$-values are -2.96 and -4.35 , respectively; both are significant at the 0.01 level. The inference from these statistics is that over-valuation of property declines with

\begin{tabular}{|c|c|}
\hline \multicolumn{2}{|c|}{$\begin{array}{l}\text { Exhibit 8. Regression Model: Difference between Assessed Value and } \\
\text { Market Value (Sale Price) }\end{array}$} \\
\hline Variable & Coefficient \\
\hline Constant & $10,509.01$ \\
\hline Price Quartile 2 & $-4,213.85^{*}$ \\
\hline Price Quartile 3 & $-6,422 \cdot 16^{* *}$ \\
\hline Price Quartile 4 & $-11,420.46^{* *}$ \\
\hline Semi-detached house & $2,321.76$ \\
\hline Detached house & $5,289.24^{*}$ \\
\hline Semi-detached bungalow & 294.16 \\
\hline Detached bungalow & $6,008.81^{*}$ \\
\hline Apartment & 635.09 \\
\hline Age & 41.88 \\
\hline Floor area & -3.16 \\
\hline Bedrooms & -897.18 \\
\hline Reception rooms & -589.58 \\
\hline Bathroom & $-2,586.45$ \\
\hline Garage & $3,483.47 * *$ \\
\hline Central heating & $5,686.39$ \\
\hline Modernization & $-1,545.98$ \\
\hline Outer north submarket & -364.14 \\
\hline South \& Lisbon submarket & $-1,643.28$ \\
\hline East \& North Down submarket & $4,956.33 * *$ \\
\hline
\end{tabular}

Notes:

* Significant at the 0.05 level.

** Significant at the 0.01 level. 
increasing price, an observation that is consistent with the analysis presented earlier. Second, positive coefficients for detached houses $(t=2.06, p=.05)$ and detached bungalows ( $t=2.07, p=.05$ ) suggests the incidence of over-valuation compared to terraced houses (omitted dummy variable). Third, the only property characteristic to be significant is the presence of a garage $(t=2.44, p=.01)$, which indicates that the model over-values those properties with a garage which, in part, explains the tendency to overvalue detached property relative to terraced property; the latter invariably do not have garages. For other property characteristics - size, number of bedrooms, number of reception rooms - there are negative relationships, which infers that as these increase, there is a greater likelihood of undervaluation. Fourth, the model indicates that properties in the East of the city are more likely to be over-valued $(t=2.87, p=.01)$, in agreement with the descriptive statistics.

\section{The Economic Effect}

This section of the paper considers the economic effect arising from the accuracy of the assessed valuations from the perspective of the revenue impact for local governments within the BMA and the effect on the level of rates (property tax) paid by householders and how this varies by property sector and location. The methodology employs the domestic rating multiple. This varies according to local authority and is supplemented by a regional rate for NI (a constant for each property) to calculate the actual rates bill for each property according to the capital value assessment as at January 2005. The same calculation is undertaken to produce an alternative rates bill based on the indexed sale price. The difference measures the economic effect of vertical tax equity/inequity on the ratepayer.

The mean annual rates bill based on assessed capital value was $£ 782.92(s=£ 412.79)$ ranging from a minimum of $£ 132$ to $£ 3,944$. The mean annual rates bill based on adjusted sales price was lower, $£ 775.65$, with a wider range $£ 115$ to $£ 4,070$ but similar standard deviation ( $£ 413.29$ ). The mean difference in annual rates bills is modest $£ 7.27$ (confidence range from -0.38 to -14.16 at the 0.05 level); it reflects the over-valuation of the assessment methodology and is statistically significant $(t=2.07, p=.04)$. If projected across all private sector households in the BMA, the additional revenue gain is $£ 1,279,520$ (confidence band from $£ 66,880$ to $£ 2,492,160$ ). ${ }^{3}$

From the perspective of the householder, the analysis shows that $20 \%$ of households have an effective reduction in their rates bill of $8 \%$ or more (equivalent to a minimum saving of $£ 51$ ) and $10 \%$ of households have a reduction in their rates bills of $15 \%$ or more (equivalent to a minimum saving of £107). This is more than offset by the greater number of households whose property has been over-valued, with $20 \%$ being over-charged at minimum an extra 9\% (at least $£ 70$ per annum) and $10 \%$ paying what is equivalent to at least an additional $17 \%$ on their rates bill (equivalent a minimum of $£ 123$ extra).

For each of the property sectors by type, with the exception of detached houses, the rates bill is higher than that calculated on the basis of adjusted sales price (Exhibit 9). In 
Exhibit 9. Difference in Rates Bill by Property Type

\begin{tabular}{lcl} 
Property Type & Difference in Rates Bill & $\boldsymbol{t}$-Statistic \\
\hline Terrace & $£ 5.46$ & 1.26 \\
Semi-detached house & $£ 12.10$ & $2.72^{* *}$ \\
Detached house & $-£ 8.45$ & 0.61 \\
Semi-detached bungalow & $£ 3.87$ & 0.32 \\
Detached bungalow & $£ 17.16$ & 1.06 \\
Apartment & $£ 20.57$ & 1.61 \\
\hline Note: & & \\
$* *$ Significant at the 0.01 level. & & \\
\hline
\end{tabular}

general, the difference in the amount payable is small; it is greatest for apartments (difference between means $=£ 20.57 ; t=1.61$ ) but only significant in the case of semidetached houses $(£ 12.10 ; t=2.72, p=.007)$. For detached houses, the opposite effect is apparent; householders are paying on average $£ 8.45(t=0.61)$ less on their rates bill but the difference is small and not statistically significant.

The economic impact on households varies spatially across the BMA (Exhibit 10). Those benefiting are households in the most affluent location: in the South of the BMA where due to under-valuation of property, householders are saving on average 21.84 per annum on their rates bill; the difference between the actual rates bill and that based on adjusted sale price is statistically significant $(t=2.47, p=0.01$ ). Across the other sectors of the city, householders are effectively paying more due to the tendency to over-value: the mean additional annual payment is $\$ 8.67$ in the West and North of the BMA $(t=1.61)$ and $£ 11.68$ in the Outer North of the BMA $(t=1.74)$. In the East of the BMA, the overvaluation of property has resulted in rate bills that are significantly higher $(£ 24.38 ; t=$ $4.06, p=.001)$ than that calculated on adjusted sale price.

Exhibit 10. Difference in Rates Bill by Location

\begin{tabular}{lcc} 
Property Area & Difference in Rates Bill & $\boldsymbol{t}$-Statistic \\
\hline North \& West city & $£ 8.67$ & 1.61 \\
Outer North & $£ 11.68$ & $1.74^{*}$ \\
South \& Lisburn & $-£ 21.84$ & $2.47^{* *}$ \\
East \& North Down & $£ 24.25$ & $4.06^{* * *}$ \\
\hline Notes: & & \\
* Significant at the 0.05 level. & & \\
** Significant at the 0.01 level. & & \\
*** Significant at the 0.001 level. & & \\
\hline
\end{tabular}




\section{Conclusion}

The accuracy and robustness of property valuations is critical particularly when it is used as the basis of a property tax for which householders will pay charges for services (rates and likely future water charges in the case of Northern Ireland). From a public policy perspective, the equity and fairness of the valuation process is an imperative; otherwise it justifiably can and will be the subject of challenges. This paper is not so much concerned with alternative valuation models or different methods of levying charges but rather seeks to analyze valuation accuracy. In particular, the extent to which valuations (assessed values) are at variance with market prices.

The main conclusion from this study is that the mass appraisal method that underpins the valuation methodology in Northern Ireland tends to over-value, rather than undervalue. The incidence of the former is more prevalent than the latter when applied to the Belfast Metropolitan Area. This pattern not only occurs in the sample as a whole, but is consistent across various sub-markets, whether it is by housing type or by location. The second key issue is that, within each of the sub-market sectors, the under-valued properties have the higher price structure and the over-valued properties have a lower price structure; a finding that is of some considerable significance regarding fairness and equity in the valuation process. Indeed, the analysis presented in this paper suggests a systematic tendency to over-value the lower-priced property. A third finding suggests the possibility of some element of spatial biasing within the process, with a higher tendency to over-value in the sub-market in the East of the BMA. The consequence of over-valuation translates into generally small differences in rates bills, although for some households the monetary impact can be substantial notably for householders in the East of the BMA.

This study raises questions regarding the differences between the assessed value and the market value, as evidenced by transaction price. Two possible explanations arise for the observed patterns and distributions. First, there is the possibility that the sample of properties in the study was in some way biased or unique. This, however, can be discounted in that the sample is relatively large $(n=1,555)$ and includes properties across different market sectors and areas throughout the BMA sold in the first half of 2005, but index-linked back to January 1, 2005. The second explanation lies in the methodology underpinning the valuation/assessment process and that either this contains some element of inbuilt systematic bias that has not been recognized by the valuers or the valuation agencies or that the range of input characteristics are too limited or too crude in the valuation of higher-priced property. This study presents evidence to support the latter and raises questions regarding the efficacy of the CAMA valuation model, as used in this instance.

\section{Endnotes}

${ }^{1}$ Northern Ireland Quarterly House Price Index undertaken by the University of Ulster is a well-established report that has been monitoring the residential market in Northern Ireland since 1985. 
2 These figures are based on un-adjusted sale price evidence.

${ }^{3}$ Based on Northern Ireland Housing Executive statistic of 176,000 private households in the BMA.

\section{References}

Allen, M.T. and W.H. Dare. Identifying Determinants of Horizontal Tax Inequity: Evidence from Florida. Journal of Real Estate Research, 2002, 24:2, 153-63.

Benson, E.D. and A.L. Schwartz. Vertical equity in the taxation of single family homes, Journal of Real Estate Research, 1997, 14:3, 215-32.

- An Examination of Vertical Equity over Two Assessment Exercises. Journal of Real Estate Research, 2000, 19:3, 255-73.

Brown, G. Property Investment and Performance Measurement: A Reply. Journal of Valuation, 1985, 4, 33-44.

- Valuation Accuracy: Developing the Economic Issues. Journal of Property Research, 1992, 9:3, 199-207.

Clapp, J.M. A New Test for Equitable Real Estate Tax Assessment. Journal of Real Estate Finance and Economics, 1990, 3, 233-49.

Crosby, N. Valuation Accuracy, Variation and Bias in the Contact of Standards and Expectations. Journal of Property Investment \& Finance, 2000, 18:2, 130-61.

Drivers Jonas/IPD. The Variance in Valuations. Drivers Jonas/Investment Property Databank. London, 1988.

—. The Variance in Valuations: Interim Report 1997. Drivers Jonas/Investment Property Databank, London, 1997.

Gallimore, P. Confirmation Bias in the Valuation Process: A Test for Corroborating Evidence. Journal of Property Research, 1996, 13, 261-73.

Geltner, D. Estimating Market Values from Appraised Values without Assuming an Efficient Market. Journal of Real Estate Research, 1993, 8, 325-45.

Haurin, D. An Empirical Analysis of Property Tax Equity. Property Tax Journal, 1988, 5-18.

Kochin, L.A. and R.W. Parks. Vertical Equity in Real Estate Assessment: A Fair Appraisal. Economic Inquiry, 1982, 20, 511-32.

Lizieri, C. and P. Venmore-Rowland. Valuation Accuracy: A Contribution to the Debate. Journal of Property Research, 1991, 8, 115-22.

Matysiak, G and P. Wang. Commercial Property Market Prices and Valuations: Analysing the Correspondence. Journal of Property Research, 1995, 12, 181-202.

McAllister, P. Valuation Accuracy: A Contribution to the Debate. Journal of Property Research, 1995, 12, 203-16.

McCluskey, W., P. Davis, and L.C. Lim. Examination of Options for a Capital Value System. Northern Ireland Rating Review Annex 1, Belfast, 2003.

McParland, C.M., W.S. McGreal, and A.S. Adair. Concepts of Price, Value and Worth in the United Kingdom: Towards a European Perspective. Journal of Property Investment and Finance, 2000, 18:1, 84-102.

Northern Ireland Executive. Reform of the Domestic Rating System in Northern Ireland. Policy Paper, Northern Ireland Assembly, Belfast, 2003.

Paglin, M. and M. Fogarty. Equity and the Property Tax: A New Conceptual Focus. National Tax Journal, 1972, 25:4, 557-65. 
RICS. RICS Appraisal and Valuation Standards. Royal Institution of Chartered Surveyors. London, 2003.

Sirmans, G.S., B.A. Diskin, and H.S. Friday. Vertical Inequity in the Taxation of Real Property. National Tax Journal, 1995, 49, 71-84.

Smith, B.C. Applying Models for Vertical Inequity in the Property Tax to a Non-Market Value State. Journal of Real Estate Research, 2000, 19:3, 321-44.

Stanley McGreal, University of Ulster-Jordanstown, Newtownabbey, Northern Ireland or ws.mcgreal@ulster.ac.uk.

Louise Brown, University of Ulster-Jordanstown, Newtownabbey, Northern Ireland or 1.brown@ulster.ac.uk.

Alastair Adair, University of Ulster-Jordanstown, Newtownabbey, Northern Ireland or as.adair@ulster.ac.uk.

James R. Webb, Cleveland State University, Cleveland, OH 44114-3610 or j.webb@csuohio.edu. 
